\title{
Economia política sob uma análise feminista materialista: a imbricação das relações sociais de sexo, raça e classe
}

\author{
Political economy under a feminist-materialist analysis: the imbrication of social relations of \\ sex, race and class \\ Mirla Cisne* \\ Jules Falquet**
}

\begin{abstract}
Resumo
Neste artigo, tem-se como objetivo, destacar algumas contribuições significativas do feminismo materialista para análise crítica da economia política do capital. Para tanto, realizou-se uma pesquisa bibliográfica, por meio da qual foi dialogado com o trabalho das feministas negras, de feministas marxistas heterodoxas e de algumas feministas e lésbicas descoloniais. Na era da mundialização neoliberal, o "trabalho desvalorizado" e "considerado feminino", gerados por corpos feminizados e/ou racializados, são marcados pela intensificação da jornada de trabalho, pela precarização e pelo trabalho gratuito. As relações de sexagem permitem que o trabalho, o corpo e o tempo das mulheres sejam apropriados gratuitamente. Já os corpos masculinos e/ou racializados são atribuídos à guerra e à segurança. Esses "homens armados" geram violência diária que mantém as "mulheres de serviço" em uma situação de precariedade e permanente excesso de trabalho. Ao mesmo tempo, garantem uma direta utilidade/reforço à economia do capital, para reconstruir o que constantemente destroem. Apenas considerando a imbricação dinâmica e dialética das relações sociais de sexo, raça e classe, em toda a sua complexidade, é que se pode pensar formas de abolir simultaneamente as desigualdades, opressões, apropriações e explorações que estruturam as desigualdades sociais.
\end{abstract}

Palavras-chave: economia política; feminismo materialista; relações sociais de sexo, raça e classe.

\begin{abstract}
In this article, we aim to highlight some significant contributions of materialist feminism to critical analysis of the political economy of capital. To this end, we conducted a literature search through which we dialogue with the work of black feminists, heterodox Marxist feminists, and some decolonial feminists and lesbians. In the era of neoliberal globalization, the "devalued" and "considered female" work performed by feminized and / or racialized bodies is marked by the intensification of the workday, precariousness and free labor. Sexual relations allow women's work, body and time to be appropriated for free. Male and / or racialized bodies are attributed to war and security. These "armed men" generate daily violence that keeps "women on duty" in a situation of precariousness and permanent overwork. At the same time, they provide a direct utility / reinforcement to the capital economy to reconstruct what they constantly destroy. Only by considering the dynamic and dialectic interweaving of social relations of sex, race, and class, in all their complexity, can we think of ways to simultaneously abolish the inequalities, oppressions, appropriations, and exploitations that structure social inequalities.
\end{abstract}

Keywords: political economy; materialistic feminism; social relations of sex, race and class.

\footnotetext{
* Doutora em Serviço Social na Universidade do Estado do Rio de Janeiro (UERJ). Professora Adjunta da Universidade do Estado do Rio Grande do Norte.

** Professora de Sociologia da Université Paris-Diderot, pesquisadora do Centre d'Enseignement, de Documentation et de Recherches pour les Etudes Féministes (CEDREF-CSPRP)
} 


\section{Introdução}

A sociedade tem sentido a agressividade da crise estrutural do capital (MÉSZÁROS, 2009), com nítidas expressões de devastação ambiental e humana. Essa crise, todavia, não se espraia de forma igualitária aos povos e nações. São os países mais pobres e, mais particularmente, as mulheres e os homens racializados e proletarizados quem sofrem os maiores impactos. Processos de (neo)colonização, com todo o seu poder destrutivo sobre os povos originários, ganham cada vez mais visibilidade, a exemplo dos grandes crimes ambientais dos últimos anos, como as queimadas que têm destruído a Amazônia e, com ela, as condições de sobrevivência dos povos indígenas e da floresta, dando continuidade ao processo, iniciado no século XVI, de genocídio, de apossamento e destruição dos recursos naturais. A incontentável expropriação desses povos é um exemplo dos limites catastróficos da era da mundialização neoliberal.

Assim, o velho se faz presente e a história parece andar para trás. A perversidade da acumulação primitiva do capital se reinventa continuamente, teimando em não ser superada. Entende-se, portanto, a acumulação primitiva não em termos meramente temporais, como algo passado, mas como ações expropriatórias nocivas ao ser humano e ao meio ambiente, logo, temporalmente também atual, agora, exercida pelo neoliberalismo. Nessa dinâmica, o racismo e o sexismo retroalimentam a lógica destrutiva do capital, pois:

[...] por meio das apropriações advindas das relações sociais de raça e sexo, o capitalismo amplia um grande contingente humano disponível para os mais baixos salários, aumentando, portanto, a sua capacidade de exploração associada às apropriações do tempo, do corpo e do trabalho não pago das mulheres. Não é possível, assim, separar as relações de produção das relações sociais, das quais as relações de sexo e raça são, indiscutivelmente, parte constitutiva (CISNE, 2018, p. 224).

Repensar esta sociedade cada vez mais agressiva ao meio ambiente e às relações humanas é mais que necessário, é urgente. Diante do aprofundamento da exploração e do impasse civilizacional que aponta para uma ameaça de extinção global colocada pela atual mundialização neoliberal, os movimentos feministas e lésbicos estão contribuindo ativamente para a busca de alternativas globais. Neste artigo, tem-se como objetivo, destacar algumas contribuições significativas do feminismo materialista para análise crítica da economia política do capital (que é também patriarcal e racista). Para tanto, realizou-se uma pesquisa bibliográfica, por meio da qual, foi dialogado com o trabalho das feministas e lésbicas negras, marxistas heterodoxas e descoloniais de Abya Yala, que permitem repensar de cima para 
baixo a lógica da reprodução social, como resultado de um processo histórico de transformação paulatina da economia política da (hetero)sexualidade até o modo de produção conhecido como capitalismo, que é simultaneamente patriarcal, racista e (neo)colonial.

\section{Aportes teórico-políticos do feminismo materialista}

Como a sua própria denominação sugere, o feminismo materialista assenta suas análises nas relações materiais, em contraposição às perspectivas culturalistas que têm seu ponto de partida e chegada na ideologia. Isso não significa dizer que o feminismo materialista desconsidera a importância da problematização da ideologia e da cultura. Muito pelo contrário. A perspectiva materialista apenas parte do entendimento de que toda ideologia está relacionada a uma base material e a relação entre ambas não pode nunca ser esquecida, tampouco a análise de uma pode ocorrer em detrimento da outra, ou seja, ambas são fundamentais.

Trata-se em outras palavras, de entender que os sistemas de dominação ideológica devem ser percebidos como "tão importantes quanto as práticas da divisão do trabalho e do poder, tão importantes quanto a dimensão material na dominação dos homens sobre as mulheres" (DEVREUX, 2011, p. 7). Assim, considerou-se que as relações materiais e ideológicas se entrelaçam e são permeadas por conflitos e disputas. Nessa mesma direção, Colette Guillaumin, uma das fundadoras do feminismo materialista francófono, de maneira enfática, afirma que as dimensões materiais e ideais são duas faces de uma mesma moeda (1992 [1978]).

Em síntese, Jules Falquet (2012, p. 137) afirma que as feministas materialistas francófonas, cuja reflexão coletiva, possivelmente, foi sintetizada mais explicitamente por Guillaumin, possuem como pontos em comum:

(1) seu anti-naturalismo, (2) a pesquisa com bases materiais e sociais [...] e (3) sua afirmação central de que as mulheres e os homens constituem classes de sexo. Além disso, algumas têm começado a utilizar o conceito de gênero, mas a maioria continua a preferir o conceito de rapports sociais de sexo, que permite evitar as derivações naturalistas ou individualizantes de algumas utilizações do gênero ( FALQUET,2012,p.137- tradução nossa).

Fundamentalmente, o destaque mais especificamente para as feministas materialistas francófonas, está em torno da transformação radical da noção de "trabalho" e a 
desnaturalização das relações sociais de raça e de sexo. Aqui, abre-se um parêntese para o entendimento da categoria relações sociais, para que se possa apreender de fato, a importância do feminismo materialista francófono.

Primeiro, cabe destacar que na língua francesa existe dois conceitos: relation e rapport, para a palavra relação. O primeiro [relation] diz respeito às relações individuais, interpessoais, cotidianas, que cada pessoa vive diretamente. São relativamente mais fáceis de serem transformadas individualmente, uma vez que são passíveis de alterações sem necessariamente haver uma transformação em relações estruturais. Isso é o que explica poder existir no campo das relações pessoais situações contrárias ao que ocorre na dinâmica das relações estruturais. Por exemplo, em uma determinada família, a mulher pode ocupar o papel de "chefe", ganhar mais que o homem e ser dominante. Isso, todavia, não altera a divisão sexual do trabalho na sociedade, a persistência das violências contra as mulheres e tampouco reflete na igualdade salarial entre os sexos. Em outras palavras, explica Mirla Cisne e Silvana Santos (2018, p. 53):

[...] nós, individualmente, por exemplo, podemos estabelecer uma alteração na nossa vivência familiar, podemos dividir igualmente as tarefas domésticas, mas essa alteração não implicará em transformação na estrutura social da divisão sexual do trabalho. Outras mulheres continuarão sendo exploradas. Assim, ainda que sejam fundamentais as mudanças no nível das relações (relations) que estabelecemos no cotidiano, para pensarmos na emancipação da mulher é preciso atingir as relações (rapports) antagônicas que estruturam as desigualdades, para nós: as relações sociais de classe, sexo e raça [...].

O segundo [rapport] é uma ferramenta teórica que designa as relações sociais estruturais, abstratas, impessoais, antagônicas e criadas dialeticamente pelas diferenças de poder entre grupos, envolvendo exploração/apropriação de um grupo sobre outro (que se torna assim uma classe). Na formulação epistemológica dominante do feminismo materialista francófono, existem três relações sociais estruturais, na medida que organizam o trabalho no seu sentido mais amplo, pago ou não: as relações sociais de sexo, raça e classe. Em outras palavras, não há apenas uma divisão de classe atravessando as sociedades, mas há, também, uma divisão sexual e racial do trabalho. "De forma mais precisa, entende-se que as relações sociais de sexo, raça e classe são antagônicas e estruturais porque determinam materialmente a exploração do trabalho, por meio da divisão de classe e da divisão sexual e racial do trabalho" (CISNE, 2018, p. 212). 
Tais relações sociais estruturais não são alteradas individualmente, ou melhor, transformações individuais não são capazes de alterá-las, apenas coletivamente, com ações que afetem a estrutura da dinâmica dessas divisões é que se torna possível transformá-las.

Feita a explanação sobre o significado de rapport, fica mais fácil entender a contribuição da análise feminista materialista: “Uma interpretação feminista da história é portanto 'materialista' no seu sentido amplo, quando suas premissas a conduzem a considerar as produções intelectuais como o produto de relações [rapports] sociais, e a considerá-las como de relações [rapports] de dominação" (DELPHY, 2009, p. 262; tradução nossa).

Nessa direção materialista, destacou-se o trabalho seminal sobre o racismo "moderno", de Colette Guillaumin (1972). Primeiramente, a autora historicizou e desnaturalizou a "raça" como uma construção social moderna que organiza materialmente e ideologicamente o modo de produção colonial do escravismo ligados à colonização do continente, agora chamado de América Latina e Caribenha. Ao dissecar a ideologia naturalista, Guillaumin revela a "raça" como um sistema de marcação física arbitrária que cria indivíduos e grupos, ancorando nos corpos uma suposta "diferença" natural que "justifica" as desigualdades sociais.

Em seguida, analisando a questão dos sexos, Guillaumin (1992[1978]) destacou a existência de relações sociais não apenas interindividuais, mas estruturais, que foram também organizadas e legitimadas pela ideologia naturalista, baseadas numa lógica de apropriação física direta das mulheres como classe de sexo pela classe dos homens. O conceito de apropriação constitui o aporte central da proposta materialista, já que diferente do marxismo que apenas considera o que acontece com a força de trabalho, Guillaumin propõe analisar o que acontece com pessoas e grupos que sequer tem a sua força de trabalho para estabelecer uma relação de troca ou venda, senão apenas o seu corpo. Corpo que não lhes pertence, já que mesmo antes de nascer e legalmente, é reificado e resumido ao que Guillaumin chama de uma "máquina de força de trabalho".

Outro ponto central nessa relação de apropriação é que, o que está sendo apropriado jamais é mensurado, nem em termos de tempo, nem de dinheiro, nem de qualquer outra forma. As relações de exploração ao contrário e como base fundamental da sua lógica, são definidas pela mensuração (em tempo e/ou dinheiro) do trabalho que está sendo comprado/vendido. Isso é precisamente o que permite pagá-lo sempre menos do que se vai ganhar ao vender o produto desse trabalho, realizando assim, a famosa "mais-valia". 
Diferente das relações de exploração, o trabalho apropriado, que poderia perfeitamente ser mensurado, não o é, e também é legalmente mantido fora do âmbito da "livre" troca. Isso é possível, precisamente, pela apropriação "prévia" da sua fonte: o próprio corpo "máquina de trabalho".

Essa apoderamento tem duas modalidades estreitamente vinculadas: a apropriação privada e a coletiva. A primeira é a mais visível e conhecida, organizada pela instituição do casamento. Mas essa apropriação privada não poderia existir sem as lógicas mais profundas e anteriores da apropriação coletiva de toda a classe das mulheres pela classe dos homens, que permitam uma clara economia de meios. Para ilustrá-la, nota-se que para "tomar uma esposa" sem ter que passar por sequestros ou guerras, os homens já devem ter firmemente estabelecido a ideia (e o fato) de que as mulheres estão obviamente disponíveis para o casamento. Os exemplos de apropriação coletiva dados por Guillaumin são principalmente, a prostituição e os conventos (sendo as freiras, coletivamente, as esposas "do Senhor").

A base ideológica da apropriação é o que Monique Wittig (1980) analisa como a "ideologia da diferença dos sexos", ou pensamento straight, quer dizer, o sistema político da heterossexualidade, nomeadamente a lógica que socialmente cria dois e apenas dois grupos sociais, o que se chama mulheres e homens. Tais grupos são considerados complementares e forçados de muitas maneiras a se unir para formar as unidades sociais de base, todavia, estão, na verdade, numa situação de poder totalmente assimétrica em vez de "complementar". Nessa assimetria, as mulheres são socialmente construídas e legalmente forçadas para dar plena atenção e cuidado aos homens (mesmo perfeitamente válidos), à prole engendrada por eles e aos indivíduos considerados como posse deles, quando são considerados inválidos.

Guillaumin denominou de sexagem [sexage] (em francês) essas relações sociais de apropriação, para destacar seus pontos em comum - em particular a lógica da apropriação física e da naturalização - com o escravismo de plantação colonial [esclavage] e a servidão medieval europeia [servage]. Numa análise do desenvolvimento do capitalismo, mas também do colonialismo escravista (onde o paulatino acesso à remuneração permitiu a alguns escravizados "comprar de volta" a sua liberdade e escapar à apropriação privada, e onde a lógica do trabalho assalariado acabou por suplantar a do feudalismo e do trabalho escravizado), Guillaumin aponta o acesso das mulheres ao trabalho assalariado como um elemento-chave na evolução da sexagem. Evolução marcada, especialmente, pela transformação de formas privadas às formas coletivas de apropriação. Aponta, ainda, 
explicitamente a existência de duas contradições: uma interna à sexagem (entre apropriação privada e coletiva), outra entre sexagem e assalariamento. Ao fazê-lo, oferece uma análise dinâmica da evolução histórica das relações sociais de sexo em relação às relações de raça e classe.

Ao mesmo tempo, colocando o racismo no centro, feministas negras socialistas estadunidenses começaram a formular a ideia do entrelaçamento de vários sistemas (BEAL, 1970[1969]; Combahee River Collective (1979); Davis 1983[1981]). Mostram a simultaneidade das relações de raça, classe e sexo, sua inseparabilidade na experiência da mulher e, sobretudo, a profundidade histórica e estrutural de suas relações.

Durante a década de 1980, as feministas marxistas europeias desenvolveram uma análise histórica internacional das ligações entre o trabalho de reprodução social e a acumulação (MIES, 1986). Na década de 1990, Glenn (2009[1992]) apontou como nos Estados Unidos, certos setores sociais específicos (mulheres e/ou racializados e/ou proletários) eram sistematicamente designados, treinados e obrigados a realizar as diversas tarefas de reprodução social. Posteriormente, a heterodoxa feminista marxista Federici (2014[2004]) argumentou que a "caça às bruxas" na Europa (e mais tarde através do Atlântico) tinha servido para criar o "espaço doméstico". No qual, desse momento em diante, ia ser realizada a maior parte do trabalho de reprodução social. Para tanto, fez-se necessário confinar dentro dele as mulheres, que antes trabalhavam tanto no campo, como na casa e de forma remunerada (mesmo que ainda não existisse o assalariamento). Isso foi, segundo Federici, o que permitiu um processo de acumulação primitiva até agora invisibilizado, mas tão importante quanto à pilhagem colonial do "Novo Mundo".

De outra perspectiva, as feministas descoloniais de Abya Yala, como Lugones (2008), depois Mendoza (2014) ou Paredes (2010), Espinosa Muñoz et al. (2014), Cabnal (2015), argumentaram que a colonização europeia tinha, desde o início, racializado e sexualizado a população colonizada e escravizada. Assim, a raça e o sexo foram essenciais na organização e divisão social do trabalho desde os primeiros momentos da gestação do capitalismo, bem antes da emergência das classes sociais, no sentido marxista.

Como extensão dessas diferentes correntes, Falquet tem trabalhado na análise da reorganização do trabalho na mundialização neoliberal. Adotando uma abordagem dialética para analisar a evolução das atividades geradoras de renda para mulheres e homens não privilegiados por raça e/ou classe, sugeriu que uma parcela significativa desses homens fosse 
agora forçada a se colocar atrás de uma arma, enquanto muitas mulheres não privilegiadas economicamente, eram empurradas para o setor de "serviços", principalmente, sexuais e domésticos. Forma-se assim, o par fatal de "homens e mulheres armados em serviços", figuras paradigmáticas da mundialização neoliberal (FALQUET, 2006).

Assim, enquanto muitos procuram definir os contornos do novo proletariado global, o que se vê é que composto por mulheres empobrecidas e proletarizadas de todas as raças, e pessoas racializadas empobrecidas e proletarizadas de todos os sexos, que são empurradas conjuntamente para realizar a maioria das atividades desvalorizadas e mal pagas de reprodução social (FALQUET, 2009).

Existe, portanto, uma dinâmica de vasos comunicantes entre as relações sociais de sexo, "raça" e classe (FALQUET, 2014): no contexto da desvinculação do Estado dos serviços e da expulsão acelerada das populações rurais, a mundialização neoliberal provocou uma profunda transformação da reprodução social, bem como a criação de uma vasta reserva de força de trabalho total ou parcialmente privada de recursos e direitos. Ao mesmo tempo, a transformação das políticas migratórias nacionais e internacionais (endurecimento e crescente seletividade) está a transformar a migração (crescimento, feminização, ilegalização) e a reorganizar profundamente a alocação do trabalho à escala global, jogando sobre as contradições e complementaridades entre diferentes formas de apropriação privada e coletiva (de sexo e raça) e exploração (de classe).

Composto, principalmente, por mulheres de todas as raças e pessoas racializadas de todos os sexos, expropriadas de suas formas anteriores de existência, o novo proletariado global é colocado em uma situação preliminar entre exploração e apropriação, em um sistema salarial precário e "feminizado", concreta e simbolicamente. Os corpos masculinos e/ou racializados são compulsoriamente empurrados à guerra e à segurança. Esses "homens armados" geram violência diária que mantém as "mulheres de serviço" em uma situação de precariedade e permanente excesso de trabalho. Ao mesmo tempo, garantem uma direta utilidade/reforço à economia do capital, para reconstruir o que eles constantemente destroem.

Já os corpos feminizados e/ou racializados desse proletariado global são maciçamente alocados à reprodução social a baixo custo. Nesse cenário, há uma intensificação das jornadas de trabalho, acompanhadas da precarização e da desvalorização da força de trabalho das mulheres. De acordo com Castro, Cisne e Oliveira (2018, p. 458-459): 
Imersas no contexto da divisão sexual do trabalho, que atribui às mulheres a responsabilidade com as tarefas necessárias à reprodução social, portanto, com o trabalho doméstico e procriativo com a criação das crianças, as mulheres estão sujeitas a uma jornada de trabalho praticamente ininterrupta. Relacionado a isso, suas atribuições são desvalorizadas, recebendo salários menores e ocupando postos de trabalho $[. .$.$] .$

Nesse mesmo sentido, Falquet nos explica a constituição do "trabalho desvalorizado" e do "trabalho considerado feminino": "[...] as mulheres efetuam sempre majoritariamente 'trabalho de mulheres' com condições de trabalho de mulheres (informalidade, precarização, abuso de todos os tipos, incluindo o assédio sexual e o plafond de verre ${ }^{1}$ ) e [sobretudo, ganhando] 'salários de mulheres'”' (FALQUET, 2012, p. 163; tradução nossa). Os conceitos de "trabalho desvalorizado" e "trabalho considerado feminino" contemplam tudo o que se encontra entre a extração de trabalho mediante salário ou algo remunerável e a extração de trabalhos gratuitos, ou seja, por meio da apropriação advinda das relações de sexagem.

Como se pode perceber, o feminismo materialista aporta contribuições fundamentais, entre as quais, destacou-se duas:

1) o desvelar do processo de organização do trabalho, com base na divisão sexual [e racial] do trabalho [...] e 2) a forma como esse trabalho é obtido, ou melhor, explorado e apropriado. Dimensão essa fundamentada, especialmente, por intermédio da categoria de apropriação advinda das relações de sexagem, elaborada por Colette Guillaumin (1992 [1978], 2005) e atualizada pelas feministas canadenses Danielle Juteau e Nicole Laurin (1988) e pela francesa Jules Falquet (2012). Aqui, destaca-se especialmente a proposição de Falquet (2012) de utilizar o conceito de "trabalho desvalorizado" como complementar ao de apropriação (CISNE, 2018, p. 138).

A análise crítica da dinâmica organizativa do trabalho e suas divisões e contradições são, sem dúvida, centrais para se pensar alternativas societárias. Na era da mundialização neoliberal, o trabalho tem sido cada vez mais explorado, apropriado e perpassado por relações alienadoras, portanto, desumanizantes. Resgatar sentidos humanos, de realização e não de alienação nas relações de trabalho, demanda a superação das divisões, explorações e apropriações que Ihes são constitutivas na sociedade capitalista, patriarcal, racista e (neo)colonial.

\footnotetext{
${ }^{1}$ A tradução literal de plafond de verre para o português seria "teto de vidro". Plafond de verre foi uma expressão cunhada nos Estados Unidos no final dos anos 1970. Em inglês é chamada glass ceiling e diz respeito a uma estrutura hierárquica, na qual os níveis superiores não são acessíveis a determinadas categorias de pessoas. Em outras palavras, essa expressão assinala a dificuldade de acesso das mulheres aos cargos superiores.
} 


\title{
Por um projeto societário feminista, anticlassista e antirracista
}

O debate sobre alternativas societárias ao capitalismo atravessa a história das organizações de esquerda, permeado por polêmicas e até mesmo contradições. Não é incomum, por exemplo, atribuir à luta feminista a culpabilização por 'dividir a classe' ou mesmo de desviar a luta de classe. Setores da esquerda, retardam assim, a construção de uma consciência revolucionária que corresponda a um projeto societário emancipatório. No entanto, para esta pesquisa:

\begin{abstract}
Não se trata de dividir, tampouco fragmentar a classe, uma ideia que lamentavelmente ainda circula em setores de esquerda, como se a luta feminista desvirtuasse o caminho da luta de classes. Trata-se, ao contrário, de entender as particularidades da classe para compreendê-la na sua totalidade, sem perder a sua unidade em particularismos identitários, que ao dar ênfase apenas às diferenças, fragmentam, isolam e perdem o que temos em comum e que nos unifica: a necessidade de um projeto coletivo classista e emancipatório. Unidade exige, todavia, o reconhecimento das diferenças. Do contrário, seria homogeneidade, e não podemos negar que a classe não é homogênea, posto que é permeada e constituída pelas relações de sexo e raça (CISNE, 2018, p. 213).
\end{abstract}

Assim, não é o feminismo, tampouco o movimento negro que divide a classe, são as relações sociais de sexo e raça que os divide, tanto no mundo do trabalho, como nos espaços sociais. Nesse sentido, explica Lélia Gonzales (1984, p. 232), percussora do feminismo negro no Brasil, sobre as divisões sociais que o racismo provoca:

O lugar natural do grupo branco dominante são moradias saudáveis, situadas nos mais belos recantos da cidade ou do campo e devidamente protegidas por diferentes formas de policiamento que vão desde os feitores, capitães do mato, capangas etc., até a polícia formalmente constituída. Desde a casa-grande e do sobrado até os belos edifícios e residências atuais, o critério tem sido o mesmo. Já o lugar natural no negro é o oposto, evidentemente: da senzala às favelas, cortiços, invasões, alagados e conjuntos "habitacionais" [...] dos dias de hoje, o critério tem sido simetricamente o mesmo: a divisão racial do espaço [...]. No caso do grupo dominado o que se constata são famílias inteiras amontoadas em cubículos cujas condições de higiene e saúde são as mais precárias. Além disso, aqui também se tem a presença policial; só que não é para proteger, mas para reprimir, violentar e amedrontar. É por aí que se entende porque o outro lugar natural do negro sejam as prisões. A sistemática repressão policial, dado o seu caráter racista, tem por objetivo próximo a instauração da submissão.

Lélia Gonzales (1984) afirma, ainda, que o racismo em articulação com o sexismo, "produz efeitos violentos sobre a mulher negra" (p. 224). Por meio dessa violência sexista e racista, naturaliza-se que mulher negra é "cozinheira, faxineira, servente, trocadora de ônibus 
ou prostituta" (IDEM, p. 226). Há, portanto, uma divisão sexual e racial do trabalho que se combinam entre si.

Outra reflexão importante trazida pela feminista negra Sueli Carneiro (2003, p. 49), é sobre as divisões entre as próprias mulheres, operadas pelas relações de classe e raça:

\begin{abstract}
Nós, mulheres negras, fazemos parte de um contingente de mulheres, provavelmente majoritário, que nunca [...] fomos tratadas como frágeis. Fazemos parte de um contingente de mulheres que trabalharam durante séculos como escravas nas lavouras ou nas ruas, como vendedoras, quituteiras, prostitutas... Mulheres que não entenderam nada quando as feministas disseram que as mulheres deveriam ganhar as ruas e trabalhar! Fazemos parte de um contingente de mulheres com identidade de objeto. Ontem, a serviço de frágeis sinhazinhas e de senhores de engenho tarados. Hoje, empregadas domésticas de mulheres liberadas e dondocas, ou de mulatas tipo exportação.
\end{abstract}

Ainda em relação ao racismo, afirma Aura Cumes, teórica guatemalteca e ativista indígena Maya Kakchikel , na sua tese de doutorado explica como as mulheres indígenas tem sido construídas historicamente como "sirvientas": não é porque sejam pobres que tem que procurar emprego em casa alheias, senão porque são indígenas, que em qualquer momento podem ser vistas e tratadas como empregadas, e empurradas ao serviço doméstico, mesmo quando conseguem estudar e tem outras qualificações laborais (CUMES, 2014).

Esses pensamentos nos levam ao entendimento de que as relações sociais não podem ser analisadas de forma isolada uma das outras. Partiu-se, portanto, da compreensão que há uma dinâmica de vasos comunicantes entre as relações sociais de sexo, "raça" e classe (FALQUET, 2014), de forma que a imbricação entre essas relações consubstanciam a materialidade das desigualdades sociais. Logo, qualquer estratégia de superação das desigualdades, exige um projeto político que seja simultaneamente e igualmente feminista, antirracista e anticapitalista.

Trata-se de entender que as relações sociais de sexo e raça, assim como as de classe, estão envoltas na dinâmica de divisão do trabalho, de produção e reprodução da vida, permeadas por antagonismos, hierarquias, contradições e explorações que, por sua vez, também se expressam em opressões. Assim, as relações sociais de sexo, raça e classe "não são contas distintas de um 'rosário' da identidade de alguém, mas sim processos interdeterminantes" (MATTHAEI, 2002, p. 44).

Esse alerta de Julie Matthaei vai ao encontro do entendimento da imbricação das relações sociais que não devem ser consideradas de forma isolada, mas sempre dialeticamente. Tampouco, devem ser apreendidas de maneira limitada ao nível individual das 
relações [relations], das identidades, mas inseridas na dinâmica dos processos sociais mais amplos, ou seja, nas relações sociais estruturais [rapports], uma vez que as alterações nas relações individuais [relations], não alteram as relações sociais [rapports]. Assim,

[...] não nos é suficiente pensar nas categorizações individuais do ser homem e do ser mulher ou mesmo nas liberdades de forma individualizada, ainda que isso também seja importante. As diversas opressões e explorações que se expressam na vida dos indivíduos são determinadas estruturalmente pelas relações sociais de sexo - incluindo sexualidade - raça e classe, que de forma imbricada e dialética configuram as múltiplas expressões da questão social, tanto na sua dimensão de desigualdade, como na de resistência política. Afinal, entendemos como relações sociais aquelas envoltas por conflitos, exploração e lutas entre grupos e classes antagônicos (CISNE, 2018. p. 212).

A transformação societária demanda, portanto, organização política coletiva. Apenas ações coletivas podem alterar as relações estruturais e, portanto, superar as desigualdades sociais. Como já afirmado, isso não significa que as transformações nas relações pessoais não sejam necessárias ou importantes, até porque não haveria coerência alguma buscar transformar a sociedade sem transformar as relações cotidiana. Apenas é necessário perceber que a ação limitada às relações individuais não consegue atingir as relações estruturais antagônicas, como já apontado anteriormente. Ou seja, “[...] para pensarmos na emancipação da mulher é preciso atingir as relações (rapports) antagônicas que estruturam as desigualdades, para nós: as relações sociais de classe, sexo e raça [...]" (CISNE; SANTOS, 2018, p. 53).

Logo, pensar projetos societários alternativos ao capitalismo patriarcal, racista e (neo)colonial, em torno da necessária construção de uma contra-hegemonia, demanda:

[...] como claramente tem afirmado Wittig, para as relações sociais de sexo abolir as relações de apropriação, a divisão do trabalho e os processos de separação e hierarquização dos grupos sociais, de construção da diferença e de naturalização dela. Em relação à apropriação de mulheres, ele implica em eliminar a divisão sexual do trabalho e o pensamento straight. Para a apropriação organizada pelas relações de "raça", a divisão internacional do trabalho, pós-colonial e relacionada a todos os tipos de colonização "interna", deverá ser abolidas, assim como da ideologia racista. Quanto à exploração de classe, são a ideologia capitalista, a propriedade privada e as relações de exploração salarial que [esse projeto político] deve tentar superar (FALQUET, 2012, p. 204; tradução nossa).

Acredita-se, portanto, ser "indispensável integrar plenamente em nossas análises os efeitos conjugados de várias relações sociais de poder: de sexo (incluso sexualidade), de classe e de 'raça' " (FALQUET, 2008, p. 122). Para tanto, é necessário considerar "sobretudo as 
interpretações das feministas racializadas e/ou proletárias e/ou lésbicas que devem [...] ser ouvidas e estudadas, se desejarmos produzir uma teoria e uma prática úteis à transformação social radical mais do que nunca necessária" (IDEM). Afinal, são essas que não apenas vivenciam as mais brutais explorações, opressões e discriminações, mas guardam ancestralmente e produzem dia após dia, capacidades de resistirem e se reinventarem.

\section{Conclusões}

A barbarização da sociedade tem sido denunciada diariamente, assim como o esgotamento das possibilidades de imprimir sentidos humanos às relações sociais que estruturam o capitalismo neoliberal. A brutalização da vida, as violências, a globalização das guerras, a precarização do trabalho, a intensificação das relações de exploração e apropriação das mulheres, são indicadores da urgente necessidade de se pensar alternativas a esta sociedade capitalista-patriarcal-racista.

Cada vez mais, as mulheres se encontram em situação de precariedade, superexploração e realizando trabalhos gratuitos, garantido grande parte da reprodução social da força de trabalho, e assim, dos ganhos econômicos, sendo, portanto, uma das sustentações fundamentais da acumulação de mais-valia. Quanto mais o Estado neoliberal restringe ou mesmo elimina direitos e políticas sociais, mais aumenta a sobrecarga pelos "serviços" e trabalhos considerados femininos. Da mesma forma, corpos masculinos e/ou racializados são empurrados à guerra e à segurança. São "homens armados" que, por um lado, geram violências, por outro, garantem um reforço à economia do capital, para reconstruir o que constantemente destroem. É a partir de romper este círculo vicioso que deve-se buscar superar as relações sociais de sexo, raça e classe, repensando completamente tanto a lógica da produção, como a da reprodução.

Apenas considerando a imbricação dinâmica e dialética das relações sociais de sexo, raça e classe, em toda a sua complexidade, é que se pode pensar formas de abolir simultaneamente as desigualdades, opressões, apropriações e explorações que estruturam o funcionamento econômico e social do mundo neoliberal globalizado. Ou seja, qualquer estratégia de superação das desigualdades, exige um projeto político feminista, antirracista e anticapitalista, comprometido com a transformação não apenas das relações econômicas/materiais, mas também, com a construção de uma contra-hegemonia emancipatória, contrária a todas ideologias conservadoras. 


\begin{abstract}
O processo de organização feminista promove, portanto, uma luta não apenas contrária ao sistema econômico restritamente falando, mas, também, aos conservadorismos patriarcais e racistas presentes nas famílias, igrejas, escolas e na estrutura burocrática do Estado. [...] A construção de uma contra-ideologia aos conservadorismos e naturalismo difundidos por essas instituições não é apenas importante, mas indispensável para a consolidação de um movimento que coloque em processo a ampliação da democracia para além dos marcos dos seus aspectos formal-institucionais, substantivando seus conteúdos em concepções, valores e ações sintonizados com a emancipação humana, com a democracia substantiva (DURIGUETTO; CISNE, 2015, p. 29).
\end{abstract}

Nesse sentindo, se entende que o feminismo radical, antirracista, orientado por uma perspectiva materialista e anticapitalista, é fundamental para um projeto alternativo de sociedade, tanto por desvelar criticamente a economia política do capital, que é racista e patriarcal, ao incorporar e reproduzir uma divisão sexual e racial, explorando e apropriando força de trabalho à baixo custo e gratuitamente; quanto porque o feminismo desnaturaliza ideologias e interfere na dinâmica concreta e cotidiana da organização da vida social. Ou seja, o feminismo busca a coerência entre pensar e agir tanto nas relações interpessoais, como nas relações estruturais, na dinâmica relacional entre rapports e relation, orientado pela e para emancipação humana.

\title{
Referências
}

BEAL, Frances. " Double Jeopardy: To Be Black and Female ». In Toni Cade Bambara (ed.). The Black Woman: An Anthology. York and Scarborough, Ontario: Mentor Books, 1970 [1969].

CABNAL, Lorena. "Corps-territoire et territoire-Terre: le féminisme communautaire au Guatemala », Cahiers du Genre, n59. Paris, 2015.

CARNEIRO, Sueli. Enegrecer o feminismo: a situação da mulher negra na América Latina a partir de uma perspectiva de gênero. In: Ashoka Empreendimentos Sociais; Takanocidadania (Orgs.). Racismos contemporâneos. Rio de Janeiro: Takano Editora, p. 49-58. 2003.

CISNE, Mirla; OLIVEIRA, Giulia; CASTRO, Viviane; Aborto inseguro: um retrato patriarcal e racializado da pobreza das mulheres. Revista Katálysis. Florianópolis, v. 21, n. 3, p. 452-470, set./dez. 2018.

CISNE, Mirla e SANTOS, Silvana. Feminismo, Diversidade Sexual e Serviço Social. Coleção Biblioteca Básica do Serviço Social. V.8. São Paulo: Cortez, 2018.

CISNE, Mirla. Feminismo e Marxismo: apontamentos teóricos-políticos para enfrentamentos das desigualdades sociais. Revista Serviço Social e Sociedade. São Paulo, n. 132, maio/ago. 2018. Disponível em: http://www.scielo.br/scielo.php?script=sci arttext\&pid=S010166282018000200211\&lng=en\&nrm=iso. Acesso em: 22 de setembro de 2019. 
COMBAHEE RIVER COLLECTIVE. « Black Feminist Statement ». In: Zillah Eisenstein, Capitalist Patriarchy and the Case for Socialist Feminism. New York: Monthly Review Press, 1979.

CUMES, Aura. "La 'índia' como 'sirvienta': servidumbre doméstica, colonialismo y patriarcado en Guatemala", Tesis para optar al grado de doctora en antropología, México, CIESAS, México, 2014.

DAVIS, Ângela. Femmes, race et classe. Paris, Des femmes, 1983 [1981].

ESPINOSA Miñoso, Yuderkys ; GÓMEZ Correal, Diana; OCHOA Muñoz, Karina (eds.). Tejiendo de otro modo: feminismo, espitemología y apuestas decoloniales en Abya Yala, Popayán, Universidad del Cauca, 2014.

DELPHY, Cristine. L'ennemi Principal. Économie Politique du Patriarcat. V.1 Paris: Éditions Syllepse, 2009.

DEVREUX, Anne-Marie. "A teoria das relações sociais de sexo: um quadro de análise sobre a dominação masculina”. In: Cadernos de Crítica Feminista. Ano V, N. 4-dez. 2011.

DURIGUETTO, Maria Lúcia e CISNE, Mirla. Feminismo e radicalização da democracia:

desafios em tempos de recrudescimento do conservadorismo no Brasil. In: Revista SER Social. V. 17, n. 36, p. 13-30. UNB, Brasília 2015.

FALQUET, Jules. "Hommes en armes et femmes "de service": tendances néolibérales dans l'évolution de la division sexuelle et internationale du travail". Cahiers du Genre, Travail et mondialisation. Confrontations Nord/Sud, $\mathrm{n}^{\circ}$ 40, pp 15-38, 2006.

FALQUET, Jules. "La règle du jeu. Repenser la co-formation des rapports sociaux de sexe, de classe et de "race " dans la mondialisation néolibérale", in Elsa Dorlin (avec la collaboration d'Annie Bidet), Sexe, race, classe. Pour une épistémologie de la domination, Paris: PUF, 2009.

FALQUET, Jules. Les mouvements sociaux dans la modialisation néolibérale: imbrication des rapports sociaux et classe des femmes (Amérique latine-Caraïbes-France). Habilitation à diriger des recherches (mimeo). Paris: Université de Paris 8, 2012.

FALQUET, Jules. "Le capitalisme néolibéral, allié des femmes? Perspectives féministes matérialistes et imbricationnistes" in: Sous le développement, le genre, Christine Verschuur, Hélène Guétat et Isabelle Guérin (coords), Paris: IRD, 2014.

FEDERICl, Silvia. Caliban et la sorcière. Femmes, corps et accumulation primitive, Marseille: Senonevero, Genève - Paris: Entremonde, 2014 [2004].

GLENN, Evelyn Nakano. "De la servitude au travail de service: les continuités historiques de la division raciale du travail reproductif payé ", in. Dorlin E. (dir.), Sexe, race, classe. Pour une épistémologie de la domination, PUF, Paris, 2009 [1992].

GONZALES, Lélia. Racismo e sexismo na cultura brasileia. Revista Ciências Sociais Hoje. Anpocs. 1984.

GUILLAUMIN, Colette. L'Id Ologie raciste: gen se et langage actuel. Paris: Walter de Gruyter, 1972 
GUILLAUMIN, Colette. Sexe, race et pratique du pouvoir. L'idée de Nature, Paris: Côté-femmes, 1992 [1978].

GUILLAUMIN, Colette, 2002 [1972], L'idéologie raciste. Paris. Gallimard, Folio Essais.

LUGONES, María. “ Colonialidad y Género », Tabula Rasa, n9, pp 73-101. Bogotá, Colombia, 2008.

MATTHAEI, Julie. "Por que os/as economistas feministas/marxistas/antirracistas devem ser economistas feministas marxistas-antirracistas". In: FARIA, Nalu e NOBRE, Miriam (orgs.). Economia Feminista. São Paulo, SOF, 2002.

MENDOZA, Breny, , Ensayos de crítica feminista en nuestra América, Mexico: Herder, 2014.

MIES, Maria, 1986, Patriarchy and Accumulation on a World Scale, Zed Books, Londres.

PAREDES, Julieta. Hilando fino desde el feminismo comunitario, La Paz, Comunidad Mujeres Creando Comunidad, Deutscher Entwicklungsdienst, 2010.

WITTIG, Monique. La pensée straight. Paris. Amsterdam, 2007 [1980]. 